\title{
Lonely hearts and angry minds: Online dating rejection increases male (but not female) hostility
}

\author{
Luca Andrighetto $^{1}{ }^{\circledR} \mid$ Paolo Riva $^{2}$ | Alessandro Gabbiadini ${ }^{2}{ }^{\circledR}$
}

${ }^{1}$ Department of Educational Science, University of Genova, Genoa, Italy

${ }^{2}$ Department of Psychology, University of Milano-Bicocca, Milan, Italy

\section{Correspondence}

Luca Andrighetto, Department of Educational Science, University of Genova, C.so Podestà, 2 - 16128, Genoa, Italy.

Email: luca.andrighetto@unige.it

\begin{abstract}
The present work explores the hostile tendencies elicited by romantic rejection in the increasingly common context of online dating. To empirically investigate this issue, we created an ad hoc online dating platform in which fictitious online dating partners romantically rejected heterosexual male and female participants. Results revealed that male-but not female-participants who were rejected by desired dating partners displayed increased hostility. This pattern of findings was consistent across different measures, which considered both aggressive tendencies against the rejecting partners and hostile attitudes against the opposite gender. Further, increased feelings of anger explained the relationship between online romantic rejection and increased male hostility.

Our work and its findings have both theoretical and methodological implications for the understanding of interpersonal processes in online interactions and the growing body of literature on online dating.
\end{abstract}

KEYWORDS

hostility, male entitlement, online dating, romantic rejection

\section{1 | INTRODUCTION}

Online dating is now a common social practice: $30 \%$ of single American adults (Pew Research Centre, 2016) and 25\% of young Europeans (Statista, 2018) report using online dating services to get to know romantic partners. This practice is deeply changing how people approach romantic relations (Finkel, Eastwick, Karney, Reis, \& Sprecher, 2012). Using these services offers advantages and disadvantages. Online dating platforms allow users to better control their self-presentation and management of interaction as opposed to a face-to-face context (Ellison, Hein, \& the Gibbs, 2006). Further, they increase the opportunities to have more and more filtered romantic encounters, especially those who have limited traditional dating channels (Rosenfeld \& Thomas, 2012). However, these increased opportunities often correspond to increased experiences of romantic rejection-especially for male users (Tyson, Perta, Haddadi, \& Seto, 2016)-that primarily happens when the desired ("liked") partner does not match the user's profile.
But how do people react to this contemporary form of rejection? Here, we developed an ostensible online dating platform to empirically address this question, by specifically focusing on users' hostile responses.

\section{ONLINE DATING LITERATURE}

Despite the popularity of online dating services, empirical research on these environments is still in its infancy (see Finkel et al., 2012 for a first review). So far, most of the research in this field has focused on why people use dating apps (Ranzini \& Lutz, 2017) or how they manage self-presentation in their online profiles. For example, some studies (Ellison et al., 2006) revealed that most daters conceive their profile as an essential means for showing others their ideal-self and, thus, often lie about characteristics they consider attractive for the potential partners (Toma, Hancock, \& Ellison, 2008). Instead, less is known about the psychological and behavioral consequences that follow the interactions of these peculiar forms of romantic 
approaches. Only a very recent work by Anderson, Holland, Koc, and Haslam (2018) considered this issue by focusing on Grindr-the largest social network app for gay and bisexual men-and revealed that gay men who use it are particularly prone to objectify other men

This work aims to contribute to this emerging field of research by considering people's reactions when rejected by a desired online partner. More specifically, we explored whether the most basic and common form of online dating rejection-the desired partner does not match the dater's profile-may per se trigger hostile responses. Addressing this issue among men is crucial because, on the one hand, they are proportionally more rejected than female daters (Tyson et al., 2016) and on the other hand, as outlined below, romantic rejection is a relevant precursor of male hostility and aggressive responses against women.

\section{3 | THE CONSEQUENCES OF ROMANTIC REJECTION}

Whether it happens in a real or virtual world, being rejected or socially excluded is a challenging experience, as it undermines our fundamental need to belong (Baumeister \& Leary, 1995). Exclusion has been associated with several negative outcomes (see Riva \& Eck, 2016 for a recent review), such as decreased personal self-esteem (Allen, vanDellen, \& Campbell, 2013; Leary, Tambor, Terdal, \& Downs, 1995) or impairment in self-regulation (Baumeister, DeWall, Ciarrocco, \& Twenge, 2006). Furthermore, socially excluded individuals commonly display increased hostility and aggressiveness towards the source of exclusion (e.g., Andrighetto, Riva, Gabbiadini, \& Volpato, 2016; Gabbiadini \& Riva, 2018; Schaafsma \& Williams 2012; Twenge, Baumeister, Tice, \& Stucke, 2001). Among the different forms of social rejection (e.g., bullying, workplace rejection), romantic rejection is one of the most traumatic and painful ones (MacDonald \& Leary, 2005). It indeed frustrates the most essential and primitive social bond, that is romantic affiliation (see Stinson, Holmes, \& He, 2011). Thus, this rejection can have relevant physical and psychological consequences, by posing a serious threat to people's self-image (Slotter, Gardner, \& Finkel, 2010) and deeply affecting their well-being (e.g., Monroe, Rohde, Seeley, \& Lewinsohn 1999; see also Baumeister \& Dhavale, 2001 for a review). Further, some works suggested possible differences in how men and women react to this form of rejection or relationship break-ups. For example, men appear to have poorer separation adjustment (Mika \& Bloom, 1980) than women. Instead, women report more than men to experience negative emotions such as sadness or confusion after rejection (Perilloux \& Buss, 2008).

Beyond having detrimental consequences for the self, romantic rejection is a possible antecedent of increased male aggressive responses against women (see, e.g., Crawford \& Gartner, 1992; Fleury, Sullivan, \& Bybee, 2000). So far, empirical studies revealed that romantic rejection interacts with specific male individual variables or female features (i.e., female sexualization) in determining male aggressiveness. For example, Downey, Feldman, and Ayduk
(2000) reported that college men who were highly sensitive to romantic rejection were more likely to engage in aggressive behaviors against their female dating partner. Further correlational studies revealed that men with higher levels of social dominance orientation (Kelly, Dubbs, \& Barlow, 2015) or masculine honor beliefs (Stratmoen, Greer, Martens, \& Saucier, 2018) tend to respond more aggressively to female's rejection and are more likely to endorse rape myths. Further, Blake, Bastian, and Denson (2018) through an experimental study revealed that young men who were romantically rejected by a sexualized (vs. non-sexualized) woman behaved aggressively because of increased sex goal activation. Considering this amount of research, in the present work, we investigated whether romantic rejection may trigger male hostility in the still unexplored social arena of online dating.

\section{4 | OVERVIEW OF THE RESEARCH}

The main goal of the present work is to test the consequences of romantic rejection in online dating platforms. To achieve this aim, we created an ad hoc online dating platform (Cupidoo) that is described below. In this platform, we experimentally manipulated romantic rejection. First, male and female heterosexual participants were asked to join the online community and match the profiles of fictitious potential partners. Then, in the experimental condition, they were romantically rejected by these fictitious partners that did not match their profile. This condition was compared with a control one, in which the online dating platform did not provide any partners' feedback. Afterward, controlling for the participants' relationship status, their hostility was assessed both in terms of aggressive tendencies against the rejecting partners and hostile attitudes against the opposite gender on the whole. We also measured participants' emotional reactions after the experience on the online platform to account for the psychological mechanisms explaining the possible link between online romantic rejection and the considered outcomes.

\section{5 | THE STUDY}

\section{1 | Method}

We report below how we determined our sample size, all data exclusions, all manipulations, and all measures in the study.

\section{2 | Participants and experimental design}

A power analysis (Faul, Erdfelder, Lang, \& Buchner, 2007) indicated that we needed a sample of 196 participants to have adequate power (0.80) to detect a medium effect $(f=0.25)$, according to our 2 (participants' gender: male vs. female) $\times 2$ (condition: romantic rejection vs. control) between-subjects design with participants' relationship status as covariate. 

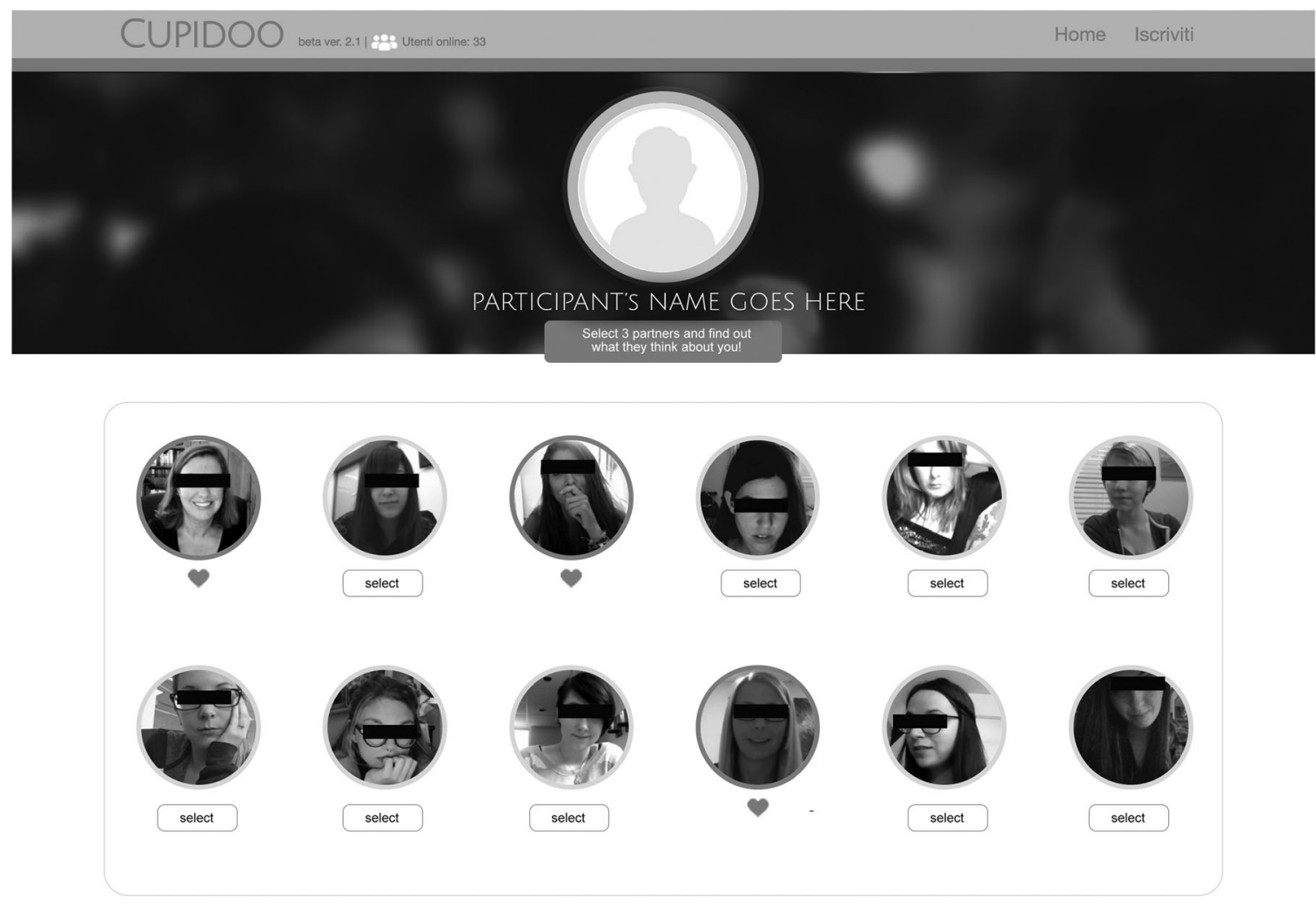

Cupidoo - Beta version v 2.1 - Copyright Cupidoo sno 2017

FIGURE 1 The selection of Cupidoo partners for male participants. All partners were presented without covering black bars

As we expected to have substantial participants' drop out due to the online administration of the study and their possible nonheterosexual orientation, we decided to collect $30 \%$ more of the planned sample size. Thus, we initially recruited 254 Italian citizens (134 female) who were randomly assigned to the romantic rejection or the control condition. These participants were recruited on a voluntary basis by four research assistants via e-mail or private message on social networks. A snowball sampling strategy was used, with the initial participants recruited through the experimenters' parental and friendship networks.

\section{3 | Exclusion criteria for participants}

Four participants were not considered because they did not complete the study, 10 because they did not agree to use their data at the end of the study, six because of a technical error. Further, to identify inattentive respondents, we included an attention check-item throughout our survey ("Please answer two to this question"; see Oppenheimer, Meyvis, \& Davidenko, 2009) and set our online software for collecting data (i.e., Qualtrics) to record the time that each respondent took for completing the study (Oppenheimer et al., 2009; see also Gabbiadini \& Greitmeyer, 2017 for a similar procedure). Ten participants were not considered because failed the attention-check item and 12 because reported very low (i.e., <15 min) or very high (i.e., $>90 \mathrm{~min}$ ) response times.

After a data inspection, 14 participants reported not being heterosexual, and three participants failed the manipulation check item (see below) and were not considered in the analyses. Thus, the final sample was composed of 195 participants (97 female; $M_{\text {age }}=$ 27.74; $S D=10.04$; age range: $18-63$ ).

\section{4 | Procedure and measures}

Participants received one out of two links to the survey, depending on their gender. As a cover story, both in the mail text and initial instructions participants were asked to test the usability of a new online dating platform, that is Cupidoo.

\subsection{1 | Online dating platform}

It was presented to participants as being designed by a fictitious company that was testing it, and that it would be released following the test phase. Participants were told that this platform was able to select the best romantic partners by considering their users' interests and photo profile. Participants were first asked to browse the platform by reading the description of the dating service and then to join the community by creating their user profile. In doing so, they were asked to describe 
themselves and their interests or hobbies by filling out a designated section that was set up so that they had to enter a minimum number of words (i.e., 100). Furthermore, they were asked to take a picture of themselves on the web camera for their profile. ${ }^{1}$

After having created their profile, participants were invited to search for possible partners. The ostensible algorithm started searching for possible partners among the other tester connected to the dating service. After $45 \mathrm{~s}$, the participant was presented with 12 different partners and asked to select the three of them s/he like the most (Figure 1).

\subsection{2 | Experimental conditions}

A computer script controlled the interactions. The web application was ad-hoc created and programmed in HTML 5, PHP, and JQuery to run two experimental conditions. In the romantic rejection condition, after the participants selected the three possible partners, all the three partners selected by the participant refused participants' request for a match. In the control condition, a warning message appeared on the screen reporting that the web application crashed, and it was therefore not possible to have the contacted users' match (see Figure 2 for examples about the two experimental conditions).

After the website experience, they were presented with three items designed to bolster the cover story (e.g., To what extent do you think that the website interface was easy to use?) and the measures which are presented below (see also the Supplementary Material). Finally, they were asked some sociodemographic variables, including their sexual orientation and relationship status. At the end of the study, a final page debriefed them about the true nature of the study.

\subsection{3 | Dependent measures}

First, as a manipulation check, participants were asked the number of users that accepted their match request. Possible answers were "no
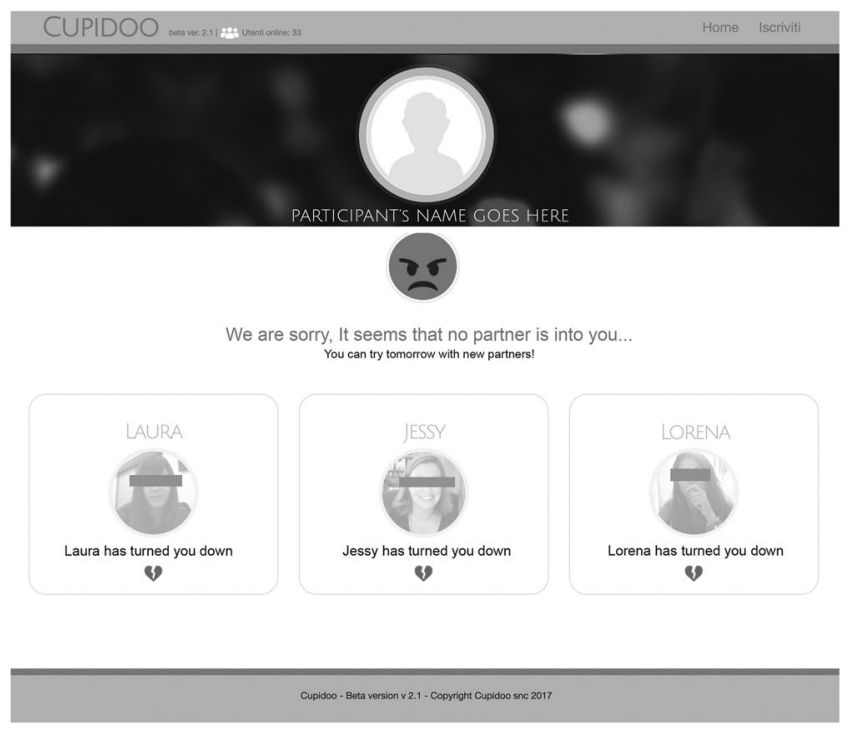

one," "one," "two," "three," "the website crashed." Then, three items $(\alpha=0.60)$ measured their perception of social exclusion ("I felt rejected"; "I felt ignored"; "I felt accepted" (R); $1=$ not at all to 7 = extremely) during their website experience.

To increase the reliability and generalizability of our test, we opted for detecting participants' hostility through three different measures.

\subsection{4 | Aggressive tendencies against online partners}

The first one measured aggressive tendencies against the online partners by employing the Malicious Humour subscale (nine items; $\alpha=0.96$ ) of the Indirect Aggression Scale (Forrest, Eatough, \& Shevlin, 2005). That is, this scale detected the extent to which ( $1=$ not at all to $7=$ extremely) participants would use a series of behaviors (e.g., using sarcasm to insult their partners, intentionally embarrassing them around others, playing a nasty practical joke) against the online partners that Cupidoo selected for them.

\subsection{5 | Hostile attitudes against the opposite gender}

The second and third measure captured participants' hostile attitudes in general toward the opposite gender. The second, that was especially meaningful for male participants, assessed participants' endorsement of myth rape beliefs ( $1=$ completely disagree to $7=$ completely agree) through the 22-item ( $\alpha=0.95$ ) of the updated version of Illinois Rape Myth Acceptance Scale (see McMahon \& Lawrence, 2011). Sample items were "If a girl goes to a room alone with a guy at a party, it is her own fault if she is raped", "If both people are drunk, it can't be rape", "A rape probably didn't happen if the girl has no bruises or marks". The third scale assessed participants' attitudes toward dating violence

FIGURE 2 Examples of Cupidoo feedback for male participants in the romantic rejection (figure on the left) and control condition (figure on the right) 
( 1 = completely disagree to $7=$ completely agree) through the Attitudes Toward Dating Violence Scale (Price, Byers, \& the Dating Violence Research Team, 1999). Depending on their gender, participants were presented with the two versions of this scale, one measuring female attitudes toward dating violence (13 items; $\alpha=0.72$; e.g., "If a girl yells and screams at her boyfriend it does not really hurt him seriously"; "It is O.K. for a girl to bad mouth her boyfriend"), the other measuring male attitudes toward dating violence (12 items; $\alpha=0.87$; e.g., "It is alright for a guy to force his girlfriend to kiss him"; "When a guy pays on a date, it is O.K. for him to pressure his girlfriend for sex").

Finally, they were asked to report the emotions they felt during their website experience ( 1 = not at all to 7 = extremely) through the Rejected-Related Emotions Scale (Buckley, Winkel, \& Leary, 2004) that measured their anger (three item; $\alpha=0.90$; e.g., "I felt angry"), happiness (three item; $\alpha=0.89$; e.g., "I felt happy"), hurt feelings (three item; $\alpha=0.80$; e.g., I felt pain), anxiety (three item; $\alpha=0.80$; e.g., I felt anxious), and sadness (three item; $\alpha=0.78$; e.g., I felt sad).

\section{5 | Analytic plan}

First, we conducted a series of 2 (participants' gender: male vs. female) $\times 2$ (condition: romantic rejection vs. control) betweensubjects analysis of covariance (ANCOVA) to verify the main effects of participants' gender, condition and their interactive effects on perception of social exclusion, the three main outcome measures assessing participants' hostility and each cluster of emotional reaction. For each ANCOVA, the participants' relationship status ( 1 = single; 0 = involved in a relationship) was entered as covariate. ${ }^{2}$ When statistically significant, the interactive effects of participants' gender $\times$ condition were probed through pairwise-comparisons with a Bonferroni correction.

After, we conducted three moderated mediation models (Preacher, Rucker, \& Hayes, 2007) by using the PROCESS macro (version 2.16.3; model 7, 5,000 iterations; Hayes, 2013) to verify the mediational role of emotional reactions in predicting participants' hostility. Each model considered one of the three hostility measures (i.e., aggressive tendencies against the online partners, myth rape acceptance and attitudes toward dating violence) as the outcome variable. In these models, condition (dummy coded, $1=$ romantic rejection; $0=$ control condition) was entered as the independent variable, participants' gender ( 1 = male; $0=$ female) as the moderator, each cluster of emotions (i.e., anger, happiness, hurt feelings, anxiety, and sadness) as mediators and participants' relationship status as a control variable.

\section{6 | RESULTS}

\section{1 | Perception of social exclusion}

Data analyses revealed a main effect of condition, $F(1,190)=103.66$, $p<.001, \eta_{p}{ }^{2}=.353$ : participants in the romantic rejection condition reported higher levels of feelings of social exclusion $(M=5.18$; $S D=1.33)$ than participants in the control condition $(M=3.39 ; S D=$ 1.09). Instead, neither the participants' gender, $F(1,190)=0.46, p=.499$, nor their relationship status, $F(1,190)=0.001, p=.983$, affected the perceptions of social exclusion. Further, the interaction participants' gender $\times$ condition was not significant, $F(1,190)=0.10, p=.753$.

\subsection{Aggressive tendencies against online partners}

Both the main effect of the condition $F(1,190)=15.33, p<.001$, $\eta_{p}{ }^{2}=.075$, and gender $F(1,190)=7.44, p=.007, \eta_{p}{ }^{2}=.038$ were significant. However, these main effects were qualified by the twoway interaction participants' gender $\times$ condition, $F(1,190)=5.77$, $p=.017, \eta_{p}{ }^{2}=.030$. Pairwise comparisons (see top panel of Figure 3) revealed that men who were romantically rejected displayed greater aggressive tendencies against the online partners $(M=2.43 ; S D=$ 1.89) compared with male participants in the control condition $(M=1.37 ; S D=0.56), F(1,190)=20.03, p<.001, \eta_{p}{ }^{2}=.095$. Instead, female participants who were romantically rejected displayed similar levels of aggressive tendencies $(M=1.52 ; S D=0.95)$ against the online male partners than women in control condition $(M=1.26$ $S D=0.43), \quad F(1,190)=1.15, p=.285$. All the effects remained significant after controlling for participants' relationship status, which affected the outcome variable, $F(1,194)=5.70, p=.018$, $\eta_{p}{ }^{2}=.029$ : overall, single participants displayed higher levels of aggressive tendencies against the online partners $(M=1.92 ; S D=$ 1.49) than the engaged ones $(M=1.40 ; S D=0.82)$.

\section{3 | Hostile attitudes against the opposite gender}

\subsection{1 | Endorsement of myth rape beliefs}

Both the main effect of the condition, $F(1,190)=5.01, p=.026$, $\eta_{p}{ }^{2}=.026$, and gender, $F(1,190)=19.56, p<.001, \eta_{p}{ }^{2}=.093$, emerged as significant. However, these main effects were qualified by the twoway interaction participants' gender $\times$ condition, $F(1,190)=10.25$, $p=.002, \eta_{p}{ }^{2}=.051$. Similar to the previous measure of aggressiveness, pairwise comparisons (see middle panel of Figure 4) revealed that male participants who were rejected by female partners endorsed more myth rape beliefs $(M=3.18 ; S D=1.69)$ than males in the control condition $(M=2.31 ; S D=0.71), F(1,190)=14.84, p<.001, \eta_{p}{ }^{2}=.072$. Instead, not surprisingly if considering this measure, female participants in the romantic rejection $(M=1.94 ; S D=0.76)$ and control condition $(M=2.08$; $S D=0.75)$ endorsed similar levels of myth rape beliefs, $F(1,190)=0.46$, $p=.500$. Importantly, the significant effects remained significant even when controlling for participants' relationship status, which did not influence the outcome variable, $F(1,194)=1.84, p=.177$.

\subsection{2 | Attitudes towards dating violence}

For this outcome variable, the experimental condition did not impact it, $F(1,190)=1.85, p=.176$, whereas gender did, $F(1,190)=7.37$, $p=.007, \eta_{p}{ }^{2}=.037$. However, their interaction was significant, $F$ $(1,190)=5.24, p=.023, \eta_{p}^{2}=.027$. Furthermore, confirming the previous pattern of findings, pairwise comparisons (see bottom panel of Figure 3) revealed that male participants who were rejected by online female partners endorsed more positive attitudes toward 


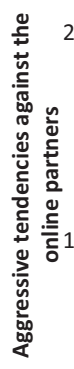

2.5

1

3.5
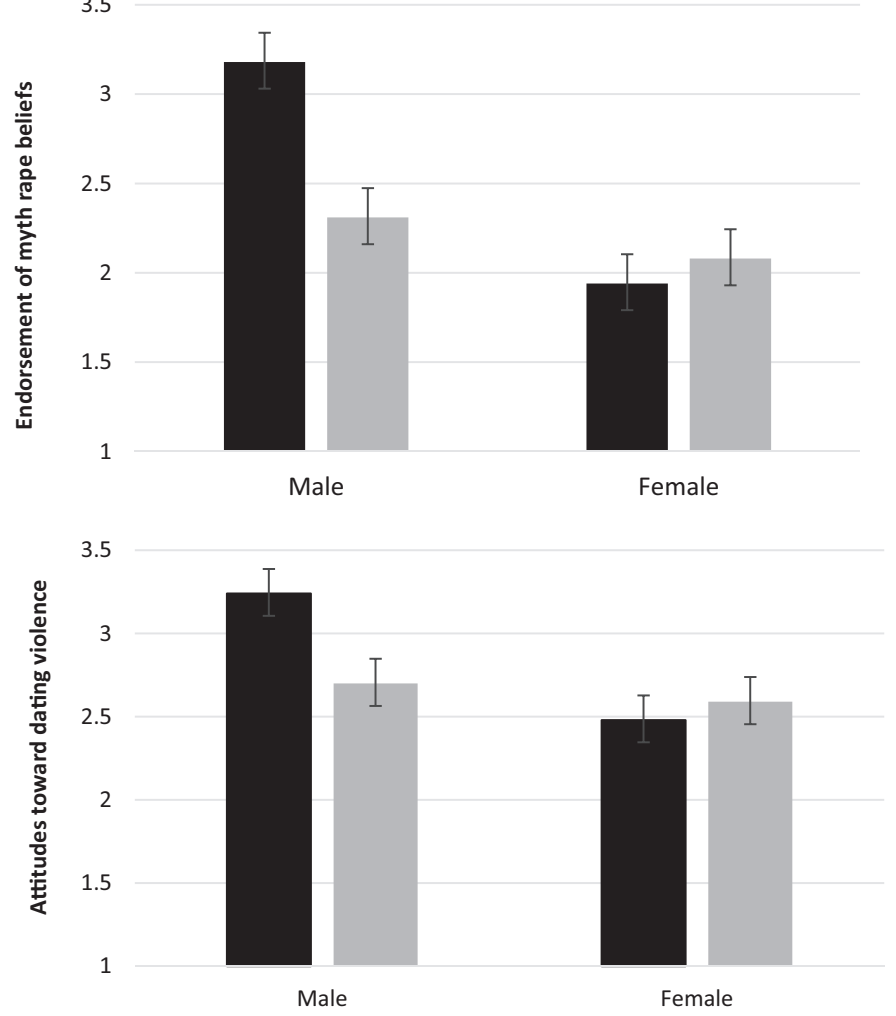

Romantic rejection

Control
FIGURE 3 Aggressive tendencies against the online partners (top panel), endorsement of myth rape beliefs (middle panel), and attitudes toward dating violence (bottom panel) as a function of participants' gender and experimental condition. Error bars represent standard errors
- Romantic rejection

Control
Romantic rejection

- Control dating violence $(M=3.24 ; S D=1.41)$ than male participants in the control condition $(M=2.70 ; S D=0.76), F(1,190)=6.67, p=.011$, $\eta_{p}{ }^{2}=.034$. Instead, female participants who were rejected by online male partners $(M=2.48 ; S D=0.64)$ had similar attitudes toward dating violence than those in the control condition $(M=2.59$; $S D=0.86), F(1,190)=0.43, p=.514$. The effects remained significant after controlling for participants' relationship status, which significantly affected this outcome variable, $F(1,190)=5.31, p=.022$, $\eta_{p}{ }^{2}=.027$ : overall, single participants displayed more positive attitudes toward dating violence $(M=3.00 ; S D=1.15)$ than participants in the control condition $(M=2.59 ; S D=0.88)$.

\section{4 | Emotional reactions}

The experimental condition significantly affected all the considered emotional reactions, $F_{s}(1,190) \geq 8.70, p_{s} \leq .004, \eta_{p}{ }^{2} \geq .044$ : participants in the romantic rejection condition displayed more anger
$(M=2.40 ; S D=1.91)$, less happiness $(M=2.28 ; S D=1.30)$, more hurt feelings $(M=2.09 ; S D=1.28)$, anxiety $(M=2.94 ; S D=1.86)$, and sadness $(M=2.26 ; S D=1.39)$ than participants in the control condition $(M=1.37 ; S D=0.86$ for anger, $M=3.33 ; S D=1.59$ for happiness, $M=1.23 ; S D=0.68$ for hurt feelings, $M=2.25 ; S D=1.36$ for anxiety, $M=1.41 ; S D=0.79$ for sadness). Further, the main effect of gender emerged for anger and happiness, $F_{s}(1,190)=5.14$, $p_{\mathrm{s}}=.025, \eta_{p}{ }^{2}=.026$ : regardless of experimental condition, male participants reported being more angry $(M=2.20 ; S D=1.95)$ and happy $(M=2.98 ; S D=1.60)$ than female participants $(M=1.57$; $S D=0.94$ for anger, $M=2.63 ; S D=1.47$ for happiness).

However, only when considering anger the above effects were qualified by the interaction between participants' gender and the experimental condition, $F(1,190)=7.68, p=.006, \eta_{p}{ }^{2}=.039$. Pairwise comparisons revealed that men who were romantically rejected by online female partners displayed more anger $(M=2.90 ; S D=2.32)$ than participants in the control condition $(M=1.35 ; S D=0.80), F$ 


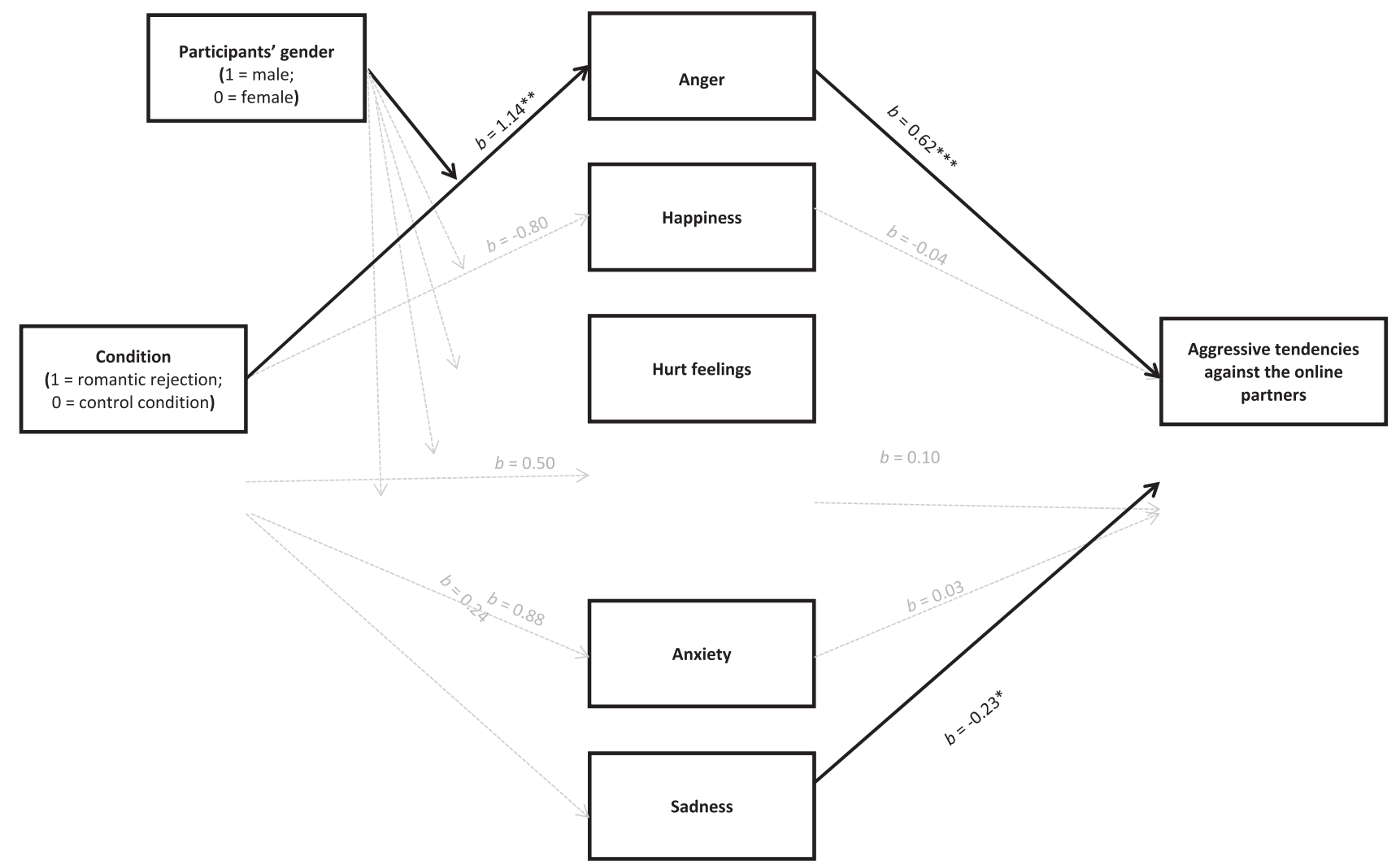

FIGURE 4 The moderated mediation model when considering aggressive tendencies against the online partners as the outcome variable. Note. $b=$ unstandardized beta weight. For the path between condition and each emotion, $b$ represents the interactive effect condition $\times$ participants' gender on each emotion. Solid paths indicate significant effects, dashed paths nonsignificant effects; ${ }^{*} p<.05 .{ }^{* *} p<.01$. ${ }^{* * *} p<.001$. Participants' relationship status was entered in the model as a control variable

$(1,190)=27.34, p<.001, \eta_{p}{ }^{2}=.126$. Instead, romantic rejection by online partners (vs. control condition) did not increase anger for female participants $(M=1.79 ; S D=0.93$ for romantic rejection condition, $M=1.39 ; \quad S D=0.91$ for control condition), $F$ $(1,190)=1.70, p=.194$. We also observed similar trends when considering happiness and anxiety, although the interactions participants' gender $\times$ condition did not reach the conventional levels of significance, $F(1,190)=3.78, p_{\mathrm{s}}=.053, \eta_{p}{ }^{2}=.019$ for happiness, $F$ $(1,190)=3.61, p=.059, \eta_{p}{ }^{2}=.019$ for anxiety. Moreover, the two-way interaction was not significant for hurt feelings and sadness, $F_{s}$ $(1,190) \leq 2.97, p_{s} \geq .087$. All the significant effects emerged regardless of participants' relationship status, which had a significant effect only when considering anxiety, $F(1,190)=8.70, p=.044, \eta_{p}{ }^{2}=.021$ : overall, single participants displayed more anxiety $(M=2.86 ; S D=$ 1.80) during their website experience that the engaged ones $(M=2.39 ; S D=1.52)$.

\section{5 | The mediational role of emotional reactions on outcome variables}

With regard aggressive tendencies against the online partners (see Figure 4), confirming the previous analyses, the interaction between participants' gender and the experimental condition positively predicted anger, $b=1.14, S E=0.41, t(4,190)=2.77, p=.006$, but not the other emotional reactions, $b_{s} \leq|0.88|, t_{s}(4,190) \leq|1.94|$, $p_{s} \geq .054$. In turn, when entered together with the experimental condition and the other cluster of emotions, anger was positively associated with aggressive tendencies against the online partners, $b=.62, S E=0.05, t(7,187)=11.34, p<.001$. Further, sadness was negatively associated with this outcome variable, $b=-0.23, S E=0.09$, $t(7,187)=-2.57, p=.011$, whereas the other emotions were not significantly associated with it, $b_{s} \leq|0.10|, t_{s}(7,187) \leq|0.92|, p_{s} \geq .357$. Most importantly, the index of moderated mediation was significant only when considering anger as a mediator, Index $=0.70, S E=0.28$, $95 \% \mathrm{Cl}(0.219,1.304)$, but not when considering the other emotions, Index $\leq|0.06|$. Finally, when the anger was the mediator, the conditional indirect effect of the experimental condition on aggressive tendencies against the online partners was greater for male, $b=.93, S E=0.28,95 \% \mathrm{Cl}(0.433,1.536)$ than female participants, $b=.23, S E=0.12,95 \% \mathrm{Cl}(0.015,0.489)$, although for both it was significant.

A similar pattern of findings also emerged for the two other measures of aggressiveness. In particular, these analyses revealed that anger was the only significant mediator for these moderated mediation models, Index $=0.72, S E=0.29,95 \% \mathrm{Cl}(0.213,1.338)$ for endorsement of myth rape beliefs, Index $=0.56, S E=0.22,95 \% \mathrm{Cl}$ (0.174, 1.027), for acceptance of dating violence (see Supporting Information Analyses for a detailed description of these analyses). 


\section{7 | GENERAL DISCUSSION}

Results from this study showed a consistent pattern of findings: on the one hand, online rejection by desired online partners increased male hostility. Such increase was reliable across different measures, that targeted both the rejecting online partners and the opposite gender overall. On the other hand, online romantic rejection did not affect female hostility: although for them this experience elicited similar levels of feelings of rejection than males, it did not affect their hostility both those against the desired online partners and those against the opposite gender.

We believe that these findings shed important light on the consequences of romantic rejection on hostile and aggressive tendencies. If considered together, they indicate that-at least in the context of online dating-this relation is gender-specific, as it concerns men but not women. To the best of our knowledge, this is the first study that empirically reveals the specificity of this link. Previous literature that explored it in real (e.g., Kelly et al., 2015) or online (Blake et al., 2018) romantic contexts only considered male participants and thus did not allow for conclusions about gender differences. We argue that both evolutionary (Ferguson \& Beaver 2009; Gottschalk \& Ellis, 2009) and sociocultural (see Murnen, Wright, \& Kaluzny, 2002) approaches can explain these findings. Among the sociocultural approaches, male entitlement may play a key role. This is a pervasive belief ingrained in the patriarchal culture that still permeates most of our societies (Bouffard, 2010). This culture implies asymmetrical power relations between men and women and includes specific male expectations about romantic relations, such as expectations of women's dependency and, indeed, a sense of entitlement in relationships with women (DeKeseredy, Rogness, \& Schwartz, 2004; Volpato, 2016). Thus, men plausibly perceive women's rejection in romantic relations as a serious threat to their interiorized masculine identity and social power (Vandello \& Cohen, 2008). Consequently, men may implicitly or explicitly view hostile and aggressive responses as a strategy to restore their threatened masculinity and to reaffirm their dominance (DeKeseredy et al., 2004; Schwartz \& DeKeseredy, 1997). The heightened endorsement of myth rape beliefs that men displayed in our study when received romantic rejection is especially representative. In fact, some men conceive rape as a means of controlling and dominating over women (Brownmiller, 1975; Pascoe \& Hollander, 2016).

Regarding our outcome measures targeting the opposite gender, on the whole, it is possible that the simultaneous rejection by three online partners in the experimental condition made the gender membership salient to our participants. This enhanced intergroup salience could contribute to explain why male participants did not only display increased aggressive tendencies against the specific source of rejection (i.e., online female partners) but also increased hostile attitudes against the female outgroup on the whole. That is, it is plausible to imagine that being rejected by (a group of) three female partners facilitated the male displacement of their activated hostility from the specific source of rejection toward the female outgroup on the whole. At the same time, if we interpret these effects in light of such intergroup salience, one should expect similar effects also for women participants, at least when considering their attitudes toward dating violence. Instead, in keeping with the other outcomes, the increased hostility after romantic rejection (vs. control condition) was gender-specific; it concerned male but not female participants. Moreover, in terms of the ecological validity of our manipulation, it is noteworthy that in most real dating apps or platforms users can be simultaneously rejected (or accepted) by more than one desired partner.

A further alternative explanation that could be put forward to interpret our overall findings is linked with the specific romantic context that we considered and with the people's motives for using online dating services. A recent survey revealed that men use them especially for having sex or seeking romantic relationships, while women use these services also for friendship and self-validation (Ranzini \& Lutz, 2016). Thus, it is possible that receiving a romantic rejection in these contexts is a more traumatic experience for men than women. However, this explanation is not supported by the reported perceptions of social exclusion and the emotions that participants felt during their online experience. In fact, like men, women who were romantically rejected reported lower levels of happiness and higher feelings of hurt, anxiety, and sadness compared with women who were assigned to the control condition. Thus, receiving online romantic rejection seems to negatively affect both women and men, at least when considering these emotions. Instead, our findings indicated that anger was more intense in men after romantic rejection. The gender-specific increase of anger may indirectly corroborate the idea that for men (but not women) being romantically rejected may undermine their sense of control and social power over women. Anger is especially elicited when people feel that their sense of control over interpersonal relations has been threatened (Frijda, 2007). Most importantly, our moderated mediation models revealed that, compared with the other emotions, anger reliably mediated the relationship between online romantic rejection and increased (male) hostility. If previous research well-established the primary role of anger in explaining the relationship between social exclusion and increased hostile and aggressive responses (see Leary, Twenge, \& Quinlivan, 2006), here we empirically demonstrated the key role of experiencing this negative feeling following romantic rejection.

Our findings also importantly contribute to a greater comprehension about the interpersonal processes featuring online interactions and, in particular, online rejections. First, for the first time, we revealed that a basic form of online rejection such as the missed match of the desired partner is enough to trigger (male) users' hostility. Past research adopted in-person manipulations (Wirth, 2016) to induce feelings of social rejection and found an increased aggressiveness towards someone who insulted and provoked the person and even towards a neutral person (Twenge et al., 2001). However, our study showed that for males, being (romantically) rejected in a virtual environment is enough to increase aggressive tendencies against the desired partners and to promote hostile attitudes against the opposite gender. 
Finally, yet importantly, we believe that our study could represent an important methodological advance for the literature on online dating. As outlined in the introduction, experimental studies that investigate the psychological processes involved in these practices are still a few, especially if compared with today's relevance of this romantic context. A possible explanation of this paucity is the difficulty of collecting experimental data from the existing online dating applications or platforms. Although the platform that we created in this study needs a more systematic validation, we believe that it could represent shortly an important tool for scholars studying these issues.

\section{1 | Limitations and future directions}

There are some limitations that should be considered in interpreting our findings and determining the direction of future research.

First, we measured aggressive tendencies only against the specific (i.e., online partners) or general (i.e., opposite gender) source of social exclusion. Thus, we cannot exclude that online rejected women displaced their aggressive tendencies against targets different than those who rejected them. Future work should detect people's aggressive tendencies after online romantic rejection by considering, for instance, a wide range of human (or nonhuman) targets. Further, a greater ecological validity of our findings can be obtained by considering measures or paradigms more directly related to online (rather than offline) aggressive behaviors against the rejecting partners.

Second, it will be important to verify whether the genderspecificity of our findings can be generalized across other romantic (i.e., face-to-face interactions) and cultural contexts. In particular, it is noteworthy that we collected our data within a specific cultural context (i.e., Italy), where the concept of male entitlement is perhaps more pervasive than other contexts. Thus, it will be crucial to verify whether these effects also emerge in less patriarchal cultures.

Third, we acknowledge that the snowball sampling adopted in our study may not be the best strategy for data collection. Similar to many other empirical works in social psychology, we chose this nonprobability sampling technique because it allowed us to recruit a rather large sample of voluntary participants. However, a greater external validity of our findings could be obtained by considering more representative samples.

Fourth, further research is needed to verify the possibility of other mediating mechanisms than the affective ones that we tested. Specifically, it could be particularly relevant to verify the mediator role of cognitive mechanisms. For instance, one could expect that for men who receive romantic rejection the increased masculinity threat could be an important factor in predicting hostile tendencies against women.

Finally, a more exhaustive picture of our findings can be obtained by considering individual differences (e.g., narcissism, Machiavellianism, and psychopathy) that could moderate the emerged effects, by inhibiting or exacerbating the aggressive tendencies of romantic rejected men.

\section{8 | CONCLUSIONS}

Romantic rejection is an experience that increases hostile male responses to women. Our study revealed that this hostility is also elicited in the virtual context of online dating platforms when the desired female partners often reject men through a simple refusal of the matching request. Given today's relevance of online dating platforms, a better understanding of the dynamics occurring in these contexts and their consequences is needed. Thus, we hope that our findings and the used methodology can encourage future studies at more systematically investigating these issues.

\section{ACKNOWLEDGMENTS}

We would like to thank Ludovica Celle, Carolina Massone, Martina Colombo, and Chiara Vignati for their help with data collection.

\section{CONFLICT OF INTERESTS}

The author(s) declared that there is no conflict of interests concerning the authorship or the publication of this article.

\section{AUTHOR CONTRIBUTIONS}

All authors developed the study concept and contributed to the study design. Data collection were organized and supervised by $P$. R. and L. A., who also performed the data analysis and drafted the manuscript. P. R. and A. G. provided critical revisions to this first draft. A. G. developed the online platform that was used in the study.

\section{ETHICS STATEMENTS}

The study was conducted after receiving ethical approval from the local Ethics Committee. All procedures performed in the study were in accordance with the AIP and APA ethical guidelines and with the 1964 Helsinki declaration and its later amendments. Full informed consent was obtained before participants started the studies.

\section{OPEN PRACTICES}

Data and materials are available through the Open Science Framework (https://osf.io/cg7pe/?view_only=5bc41d1b35b84dc1978f1ca1c88ae6 17).

\section{ENDNOTES}

${ }^{1}$ The described paradigm (Cupidoo) is currently under further development and validation and will be soon publicly released on the Internet. The original code is available upon request directly to the authors.

2 For each outcome variable, a similar pattern of finding emerged also when not considering the status relationship as covariate (see the Supporting Information Analyses). 


\section{ORCID}

\section{Luca Andrighetto (D) http://orcid.org/0000-0001-6257-6097 \\ Alessandro Gabbiadini (D) http://orcid.org/0000-0002-7593-8007}

\section{REFERENCES}

Allen, A. B., vanDellen, M. R., \& Campbell, W. K. (2013). Individual differences in responses to social exclusion: Self-esteem, narcissism, and self-compassion. In N. C. DeWall (Ed.), The Oxfornd Handbook of Social Exclusion (pp. 220-227). Oxford, UK: Oxford University Press. https://doi.org/10.1093/oxfordhb/9780195398700.013.0020

Anderson, J. R., Holland, E., Koc, Y., \& Haslam, N. (2018). iObjectify: Selfand other-objectification on grindr, a geosocial networking application designed for men who have sex with men. European Journal of Social Psychology, 48, 600-613. https://doi.org/10.1002/ejsp.2350

Andrighetto, L., Riva, P., Gabbiadini, A., \& Volpato, C. (2016). Excluded from all humanity: Animal metaphors exacerbate the consequences of social exclusion. Journal of Language and Social Psychology, 35, 628-644. https://doi.org/10.1177/0261927X16632267

Baumeister, R. F., DeWall, C. N., Ciarrocco, N. L., \& Twenge, J. M. (2006). Social exclusion impairs self-regulation. Journal of Personality and Social Psychology, 88, 589-604. https://doi.org/10.1037/0022-3514. 88.4.589

Baumeister, R. F., \& Dhavale, D. (2001). Two sides of romantic rejection. In M. R. Leary (Ed.), Interpersonal Rejection (pp. 55-72). Oxford, UK: Oxford University Press. https://doi.org/10.1093/acprof:oso/9780195130157. 003.0003

Baumeister, R. F., \& Leary, M. R. (1995). The need to belong: Desire for interpersonal attachments as a fundamental human motivation. Psychological Bulletin, 117, 497-529. https://doi.org/10.1037/00332909.117.3.497

Blake, K. R., Bastian, B. B., \& Denson, T. F. (2018). Heightened male aggression toward sexualized women following romantic rejection: The mediating role of sex goal activation. Aggressive Behavior, 44, 40-49. https://doi.org/10.1002/ab.21722

Bouffard, L. A. (2010). Exploring the utility of entitlement in understanding sexual aggression. Journal of Criminal Justice, 38, 870-879. https://doi.org/10.1016/j.jcrimjus.2010.06.002

Brownmiller, S. (1975). Against our will: Men, women, and rape, London, UK: Pelican Books.

Buckley, K. E., Winkel, R. E., \& Leary, M. R. (2004). Reactions to acceptance and rejection: Effects of level and sequence of relational evaluation. Journal of Experimental Social Psychology, 40, 14-28. https://doi.org/10.1016/S0022-1031(03)00064-7

Crawford, M., \& Gartner, R. (1992). Women killing: Intimate femicide in Ontario (pp. 1974-1990). Toronto: Women We Honour Action Committee.

DeKeseredy, W. S., Rogness, M., \& Schwartz, M. D. (2004). Separation/ divorce sexual assault: The current state of social scientific knowledge. Aggression and Violent Behavior, 9, 675-691. https://doi.org/10. 1016/j.avb.2003.08.004

Downey, G., Feldman, S., \& Ayduk, O. (2000). Rejection sensitivity and male violence in romantic relationships. Personal Relationships, 7 , 45-61. https://doi.org/10.1111/j.1475-6811.2000.tb00003.x

Ellison, N. B., Heino, R., \& Gibbs, J. (2006). Managing impressions online: Self-presentation processes in the online dating environment. Journal of Computer-Mediated-Communication, 11, 415-441. https://doi.org/ 10.1111/j.1083-6101.2006.00020.x

Faul, F., Erdfelder, E., Lang, A. G., \& Buchner, A. (2007). G*Power 3: A flexible statistical power analysis program for the social, behavioral, and biomedical sciences. Behavior Research Methods, 39, 175-191.

Ferguson, C. J., \& Beaver, K. M. (2009). Natural born killers: The genetic origins of extreme violence. Aggression and Violent Behavior, 14, 286-294. https://doi.org/10.1016/j.avb.2009.03.005
Finkel, E. J., Eastwick, P. W., Karney, B. R., Reis, H. T., \& Sprecher, S. (2012). Online dating: A critical analysis from the perspective of psychological science. Psychological Science in the Public Interest, Supplement, 13, 3-66. https://doi.org/10.1177/1529100612436522

Fleury, R. E., Sullivan, C. M., \& Bybee, D. I. (2000). When ending the relationship does not end the violence: Women's experiences of violence by former partners. Violence Against Women, 6, 1363-1383. https://doi.org/10.1177/10778010022183695

Forrest, S., Eatough, V., \& Shevlin, M. (2005). Measuring adult indirect aggression: The development and psychometric assessment of the Indirect Aggression Scales. Aggressive Behavior, 31, 84-97. https://doi. org/10.1002/ab.20074

Frijda, N. H. (2007). The laws of emotion. Mahwah, NJ: Erlbaum.

Gabbiadini, A., \& Greitmeyer, T. (2017). Uncovering the association between strategy video games and self-regulation: A correlational study. Personality and Individual Differences, 104, 129-136. https://doi. org/10.1016/j.paid.2016.07.041

Gabbiadini, A., \& Riva, P. (2018). The lone gamer: Social exclusion predicts violent video game preferences and fuels aggressive inclinations in adolescent players. Aggressive Behavior, 44, 113-124. https://doi.org/ 10.1002/ab.21735

Gibbs, J. L., Ellison, N. B., \& Heino, R. (2006). Self-presentation in online personals: The role of anticipated future interaction, self-disclosure, and perceived success in Internet dating. Communication Research, 33, 1-26.

Gottschalk, M., \& Ellis, L. (2009). Evolutionary and genetic explanations of violent crime. In C. Ferguson (Ed.), Violent crime: Clinical and social implications (pp. 57-74). Thousand Oaks, CA: Sage. https://doi.org/10. 4135/9781483349305.n4

Hayes, A. F. (2013). An introduction to mediation, moderation, and conditional process analysis: A regression-based approach. New York, NY: Guilford Press.

Kelly, A. J., Dubbs, S. L., \& Barlow, F. K. (2015). Social dominance orientation predicts heterosexual men's adverse reactions to romantic rejection. Archives of Sexual Behavior, 44, 903-919. https://doi.org/. org/10.1007/

Leary, M. R., Tambor, E. S., Terdal, S. K., \& Downs, D. L. (1995). Self-esteem as an interpersonal monitor: The sociometer hypothesis. Journal of Personality and Social Psychology, 68, 518-530. https://doi.org/10. 1037/0022-3514.68.3.518

Leary, M. R., Twenge, J. M., \& Quinlivan, E. (2006). Interpersonal rejection as a determinant of anger and aggression. Personality and Social Psychology Review, 10, 111-132. https://doi.org/10.1207/ s15327957pspr1002_2

MacDonald, G., \& Leary, M. R. (2005). Why does social exclusion hurt? The relationship between social and physical pain. Psychological Bulletin, 131, 202-223. https://doi.org/10.1037/0033-2909.131.2.202

McMahon, S., \& Lawrence, G. F. (2011). An updated measure for assessing subtle rape myths. Social Work Research, 35, 71-81. https://doi.org/10. 1093/swr/35.2.71

Mika, K., \& Bloom, B. L. (1980). Adjustment to separation among former cohabiters. Journal of Divorce, 4, 45-66. https://doi.org/10.1300/ J279v04n02_04

Monroe, S. M., Rohde, P., Seeley, J. R., \& Lewinsohn, P. M. (1999). Life events and depression in adolescence: Relationship loss as a prospective risk factor for first onset of major depressive disorder. Journal of Abnormal Psychology, 108, 606-614. https://doi.org/10. 1037//0021843X.108.4.606

Murnen, S. K., Wright, C., \& Kaluzny, G. (2002). If "boys will be boys," then girls will be victims? A meta-analytic review of the research that relates masculine ideology to sexual aggression. Sex Roles, 46, 359-375. https://doi.org/10.1023/A:1020488928736

Oppenheimer, D., Meyvis, T., \& Davidenko, N. (2009). Instructional manipulation checks: Detecting satisficing to increase statistical power. Journal of Experimental Social Psychology, 45, 867-872. https://doi.org/10.1016/j.jesp.2009.03.009 
Pascoe, C. J., \& Hollander, J. A. (2016). Good guys don't rape: Gender, domination, and mobilizing rape. Gender \&. Society, 30, 67-79. https:// doi.org/10.1177/0891243215612707

Perilloux, C., \& Buss, D. M. (2008). Breaking up romantic relationships: Costs experienced and coping strategies deployed. Evolutionary. Psychology, 6 164-181. https://doi.org/10.1177/147470490800600119

Pew Research Centre. (2016 (). The never-been-married are biggest users of online dating. Retrieved from September 1 2018, from http://www. pewresearch.org/fact-tank/2016/02/18/the-never-been-married-arebiggest-users-of-online-dating/

Preacher, K. J., Rucker, D. D., \& Hayes, A. F. (2007). Addressing moderated mediation hypotheses: Theory, methods, and prescriptions. Multivariate Behavioral Research, 42, 185-227. https://doi.org/10.1080/ 00273170701341316

Price, E. L., \& Byers, E. S., the Dating Violence Research Team. (1999). The attitudes towards dating violence scales: Development and initial validation. Journal of Family Violence, 14, 351-375. https://doi.org/10. 1023/A:1022830114772

Ranzini, G., \& Lutz, C. (2017). Love at first swipe? Explaining Tinder selfpresentation and motives. Mobile Media \& Communication, 5, 80-101. https://doi.org/10.1177/2050157916664559

Riva, P., \& Eck, J. (2016). Social exclusion: Psychological approaches to understanding and reducing its impact. New York, NY: Springer.

Rosenfeld, M., \& Thomas, R. (2012). Searching for a mate: The rise of the internet as a social intermediary. American Sociological Review, 77, 523-547. https://doi.org/10.1177/0003122412448050

Schaafsma, J., \& Williams, K. (2012). Exclusion, intergroup hostility, and religious fundamentalism. Journal of Experimental Social Psychology, 48, 429-437. https://doi.org/10.1016/j.jesp.2012.02.015

Schwartz, M. D., \& DeKeseredy, W. S. (1997). Sexual assault on the college campus: The role of male peer support, Thousand Oaks, CA, US. Sage Publications, Inc.

Slotter, E. B., Gardner, W. L., \& Finkel, E. J. (2010). Who am I without you? The influence of romantic breakup on the self-concept. Personality and Social Psychology Bulletin, 36, 147-160. https://doi.org/10.1177/ 0146167209352250

Statista (2018 (). Online dating. Statistics \& Facts. Retrieved September 1 2018, from https://www.statista.com/topics/2158/online-dating/

Stinson, D. A., Holmes, J. G., \& He, T. H. (2011). Rejection in romantic relationships. In K. D. Williams, \& S. A. Nida (Eds.), Ostracism, social exclusion and rejection (pp. 164-176). New York, NY: Psychology Press.
Stratmoen, E., Greer, M. M., Martens, A. L., \& Saucier, D. A. (2018). What, I 'm not good enough for you? Individual differences in masculine honor beliefs and the endorsement of aggressive responses to romantic rejection. Personality and Individual Differences, 123, 151-162. https:// doi.org/10.1016/j.paid.2017.10.018

Toma, C., Hancock, J. T., \& Ellison, N. B. (2008). Separating fact from fiction: An examination of deceptive self-presentation in online dating profiles. Personality and Social Psychology Bullettin, 34, 1023-1036. https://doi.org/10.1177/0146167208318067

Twenge, J. M., Baumeister, R. F., Tice, D. M., \& Stucke, T. S. (2001). If you can't join them, beat them: Effects of social exclusion on aggressive behavior. Journal of Personality and Social Psychology, 81, 1058-1069. https://doi.org/10.1037//0022-3514.81.6.1058

Tyson, G., Perta, V. C., Haddadi, H., \& Seto, M. (2016). A first look at user activity on Tinder, Proceedings of the 2016 IEEE/ACM International Conference on Advances in Social Networks Analysis and Mining, ASONAM 2016 (pp. 461-466). San Francisco, US: Institute of Electrical and Electronics Engineers Inc.

Vandello, J. A., \& Cohen, D. (2008). Culture, gender, and men's intimate partner violence. Social and Personality Psychology Compass, 2, 652-667. https://doi.org/10.1111/j.1751-9004.2008.00080.x

Volpato, C. (2016). Psicosociologia del maschilismo [Social Psychology of masculism], Bologna, Italia: Laterza Editore.

Wirth, J. H. (2016). Methods for investigating social exclusion. In P. Riva, \& J. Eck (Eds.), Social exclusion: Psychological approaches to understanding and reducing its impact (pp. 199-225). New York, NY: Springer.

\section{SUPPORTING INFORMATION}

Additional supporting information may be found online in the Supporting Information section.

How to cite this article: Andrighetto L, Riva P, Gabbiadini A. Lonely hearts and angry minds: Online dating rejection increases male (but not female) hostility. Aggressive Behavior. 2019;1-11. https://doi.org/10.1002/ab.21852 